\title{
A PRÁTICA NA PRÁTICA: COMO APRENDER CONTABILIDADE POR MEIO DE UMA ATIVIDADE ON LINE?
}

\author{
UBERABA/MG JULHO/2018

\begin{abstract}
CAMILLA DE OLIVEIRA VIEIRA - Uniube - gestor.administracao@uniube.br GILMAR GONÇALVES DA SILVA JÚNIOR - UNIUBE - gilmar.silva@uniube.br SÉRGIO QUERINO ANTUNES - UNIUBE - sergio.antunes@uniube.br
\end{abstract} \\ SILVIA DENISE DOS SANTOS BISINOTTO - UNIUBE - silvia.bizinoto@uniube.br
}

\author{
Tipo: Relato de Experiência Inovadora (EI) \\ Categoria: Conteúdos e Habilidades \\ Setor Educacional: EDUCAÇÃO SUPERIOR
}

\begin{abstract}
RESUMO
Frente a um cenário cada vez mais competitivo em que as organizações estão inseridas, os cursos da Universidade de Uberaba se preocupam em formar profissionais preparados para lidar com situações que exigem tomada de decisões. Referido desafio está fortemente relacionado à formação profissional na medida em que a indissociabilidade entre teoria e prática, o desenvolvimento de uma visão integral do homem e a compreensão de uma cultura globalizada tornaram-se pressupostos para a adequada atuação de quem se dispõe a enfrentar o mercado de trabalho atual. Neste sentido, a disciplina Contabilidade Gerencial e Análise de Custos propõe uma experiência prática interdisciplinar que visa a inserção do aluno em um cenário construído para integrar uma equipe de consultoria contratada com o objetivo de revisar o sistema de custeio de uma indústria fictícia. O aluno é conduzido a propor uma solução para uma situação específica e, ao final, emitir um relatório contendo seu parecer técnico, conforme é feito no dia a dia de uma empresa de consultoria real. Por fim, a produção deste artigo com objetivo de socializar esta experiência se justifica, tendo em vista que refletir sobre situações vivenciadas no processo de ensino-aprendizagem contribuem para a busca da melhoria da qualidade de ensino por parte dos envolvidos na educação superior.
\end{abstract}

Palavras-chave: Metodologias ativas. Contabilidade. Avaliação 


\section{O contexto institucional da EAD-UNIUBE}

Em Junho de 2005, a UNIUBE foi credenciada pelo MEC para oferecer formação superior a distância, pela Portaria $n^{\circ}$ 1.871. Em 2005 promoveu o $1^{\circ}$ processo seletivo em três polos e hoje a Instituição, presente em vários estados brasileiros oferta bacharelados, licenciaturas, tecnológicos e pós-graduação por meio de mais de 100 polos credenciados.

A EAD na UNIUBE consolida-se em uma prática educativa de interação pedagógica, cujos objetivos, conteúdos e resultados obtidos identificam-se com aqueles que caracterizam a educação como projeto e processo humano histórico e politicamente definido na cultura das diferentes sociedades. Busca valorizar a pesquisa e a investigação e volta-se para a construção de competências e atitudes, respeitando-se o ritmo individual do aluno e o desenvolvimento de sua autonomia. Por meio da EAD, a UNIUBE tem como objetivos: contribuir para a democratização das oportunidades educacionais e para o desenvolvimento sociocultural, científico e autossustentável do país; colaborar para a qualificação e constante atualização profissional do cidadão, de acordo com as inovações tecnológicas e contínuas mudanças nos processos de trabalho; promover a educação continuada e permanente a distância; favorecer e orientar o exercício da autonomia, a fim de que cada pessoa seja capaz de construir sua própria situação de aprendizagem, tornando-se sujeito transformador dos diversos ambientes em que atua.

As metas institucionais para a EAD traduzem-se em posturas e ações que visam atrair (mais e melhores alunos); acolher (os ingressantes); otimizar (o uso de recursos sem desperdício); fidelizar (por meio da satisfação dos alunos); agregar "valor" (aos egressos); empregar (aproximação com o mercado).

\section{A proposta da disciplina Contabilidade Gerencial e Análise de Custos}

Os cursos na modalidade a distância de Administração, Ciências Contábeis, e Gestão Financeira da Universidade de Uberaba possuem em seus currículos a disciplina Contabilidade Gerencial e Análise de Custos respectivamente nas etapas 6, 4 e 4. Tratase de uma disciplina cujo objetivo principal seja possibilitar ao aluno identificar os fundamentos teóricos e práticos necessários para gestão de custos bem como avaliar diversos conceitos e técnicas normalmente usadas no planejamento, controle, operação e em processos de tomada de decisão.

A fim de atingir este objetivo os envolvidos no processo de formação superior da 
Universidade de Uberaba têm sido estimulados a (re) pensar as transformações necessárias ao ensino reconhecendo seu papel social e enfrentando os desafios da globalização, entre os quais o de questionar as rígidas estruturas dos modelos de ensino tradicionais e propor atividades que oportunizam o aluno a vivenciar experiências sendo capaz de refletir e atuar sobre elas.

A escolha por uma metodologia requer responsabilidade acerca das competências e habilidades desejadas e transforma-se em uma importante estratégia para uma prática pedagógica questionadora, crítica e transformadora que ultrapasse as barreiras do conhecimento meramente técnico. Ferreira et al., (2011) observaram em seu estudo que as metodologias de ensino mais utilizadas pelas universidades norte-americanas pesquisadas em Contabilidade de Custos são as "Aulas expositivas" e "Atividades para casa", correspondendo a $100 \%$ da amostra. Foram evidenciadas também: "Atividades em aula", "Quizzes", "Trabalhos em grupo" e "Estudo de caso", perfazendo 50\% da amostra; seguidos pelas "Revisões semanais" e "Seminários", equivalente a 12,5\%.

Uma crítica muito comum dentre os estudiosos de Contabilidade é que no contexto educacional as metodologias tradicionais de ensino aprendizagem não estão sendo suficientes para desenvolver, nos profissionais, competências necessárias à atuação multidisciplinar que os possibilite a tomada de decisão em diversos segmentos de uma organização (BARBOSA; MOURA, 2013).

Segundo Silva e Scapin (2011), o uso de metodologias ativas, que considerem o estudante como ator principal, estimula o raciocínio crítico, a pesquisa, a reflexão, a análise e decisão, proporcionado, sobretudo, a capacidade de aprender a aprender. Neste sentido, o aluno abre mão da passividade e passa a ocupar uma posição ativa no processo de ensino-aprendizagem. Destaca-se que o ensino da disciplina de Contabilidade de Custos no contexto nacional é um desafio, pois, de acordo com Koliver (1994), a maioria dos estudantes dos cursos de Ciências Contábeis não possui conhecimento mínimo sobre equipamentos e processos, tanto nas indústrias de manufatura como de processamento, aumentando em outros segmentos econômicos como da mineração, agricultura, pecuária e prestação de serviços.

Complementa Reis, Tarifa e Nogueira (2009), que nas disciplinas de Contabilidade de Custos e Contabilidade Gerencial, dos cursos de Ciências Contábeis e demais áreas de gestão, o uso de novas estratégias pedagógicas aliadas à tecnologias inovadoras contribui para formação de profissionais com competências necessárias ao desenvolvimento profissional e pessoal. É sob esta perspectiva que socializamos aqui uma proposta de atividade multidisciplinar pela qual o aluno é incentivado ao longo do 
curso a conhecer e aplicar as técnicas de Contabilidade Gerencial e de Custos na tomada de decisões conceituando e demonstrando a aplicação das metodologias contábeis. Ela se justifica uma vez ser fundamental que o aluno desenvolva em sua formação, a competência para identificar e demonstrar a aplicação dos resultados da Contabilidade Gerencial e de Custos na otimização dos resultados econômicofinanceiros de uma organização.

Neste sentido, a disciplina cumpre o previsto nos projetos pedagógicos dos cursos possibilitando a formação de um aluno egresso capaz de ser um profissional empreendedor que formula e toma decisões estratégicas, consciente de sua responsabilidade social, capacitado para atuar de forma flexível e tomar decisões a partir da compreensão das questões científicas, técnicas, sociais e econômicas da produção e de seu gerenciamento, com competência para:

a) utilizar adequadamente os recursos de comunicação e expressão em situações relacionadas ao exercício profissional, expressando-se de modo crítico e criativo frente aos diferentes contextos organizacionais e sociais; $b$ ) ter atitude persuasiva e influente nos relacionamentos interpessoais e intergrupais; c) reconhecer as diferentes características das organizações para elaborar, implementar e consolidar projetos que sejam exequíveis; d) ponderar as influências externas na tomada de decisões, com capacidade crítica, analítica e de síntese; e) buscar informações e oportunidades de negócios, pensar estrategicamente e agir de forma criativa; f) identificar, mensurar, assumir e conviver com riscos; g) ser capaz de resolver problemas de forma a atuar preventivamente, com base em conhecimentos que o auxiliem no processo de tomada de decisões; $h$ ) buscar permanentemente resultados tendo iniciativa, determinação e vontade política e administrativa; i) usar apropriadamente as novas tecnologias de informação, e j) ser capaz de realizar consultoria em gestão e administração, emitir pareceres e perícias administrativas, gerenciais e organizacionais.

A fim de contribuir para que o aluno construa referidas competências, a atividade prática será descrita a seguir, cuja ênfase é contribuir para o aluno aplicar os conhecimentos de forma interdisciplinar, relacionando a teoria e prática.

\section{A atividade prática de Contabilidade Gerencial e Análise de Custos}

Trata-se de uma atividade interdisciplinar que visa a inserção do aluno em um cenário construído para integrar uma equipe de consultoria contratada com o objetivo de revisar o sistema de custeio de uma indústria também fictícia. $O$ aluno é conduzido a propor uma solução para uma situação específica e, ao final, emitir um relatório contendo seu parecer técnico, conforme é feito no dia a dia de uma empresa de consultoria real.

\section{Como a atividade é desenvolvida?}

Para realizar a atividade o aluno efetua o download da planilha elaborada em Excel disponível no AVA (Ambiente Virtual de Aprendizagem) da disciplina Contabilidade 
Gerencial e Análise de Custos. Todo o desenvolvimento da resposta será feito diretamente na planilha preparada por professor de diferentes áreas da gestão. Primeiramente o aluno insere seu nome e RA (registro acadêmico) na aba chamada Identificação, demonstrada na figura 1. Neste momento a planilha realiza um cálculo com base nos números fornecidos pelo aluno e cria um fator multiplicador para todos os valores presentes na questão. Desta forma, a questão torna-se individual, ou seja, cada aluno terá uma proposta diferente com dados exclusivos.

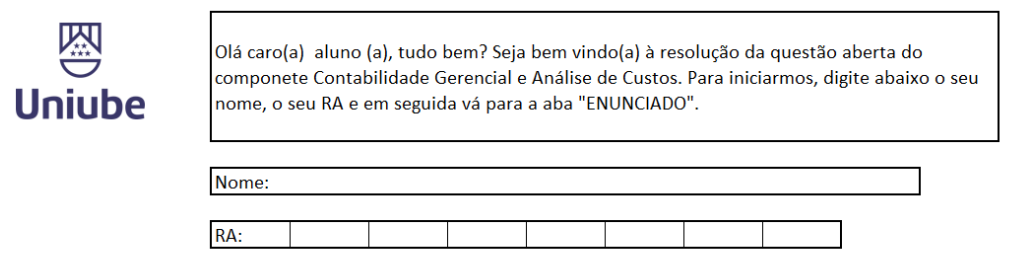

\begin{tabular}{l|l|l|l|l|l|l} 
Identificação & ENUNCIADO & CLASSIF. CUSTOS E DESPESAS & MAPA DE CUSTOS ATUAL & DEPARTAMENTALIZAÇÃO & PROP. NOVO MAPA DE CUSTOS & RELATÓRIO DO CONSULTOR \\
\hline
\end{tabular}

Figura 1 - Identificação

Após ter a sua atividade criada, o aluno é orientado a abrir a aba intitulada Enunciado, demonstrada na figura 2, onde estão todos os dados necessários para a resolução, inclusive aqueles gerados a partir do cálculo efetuado pela planilha na etapa anterior.

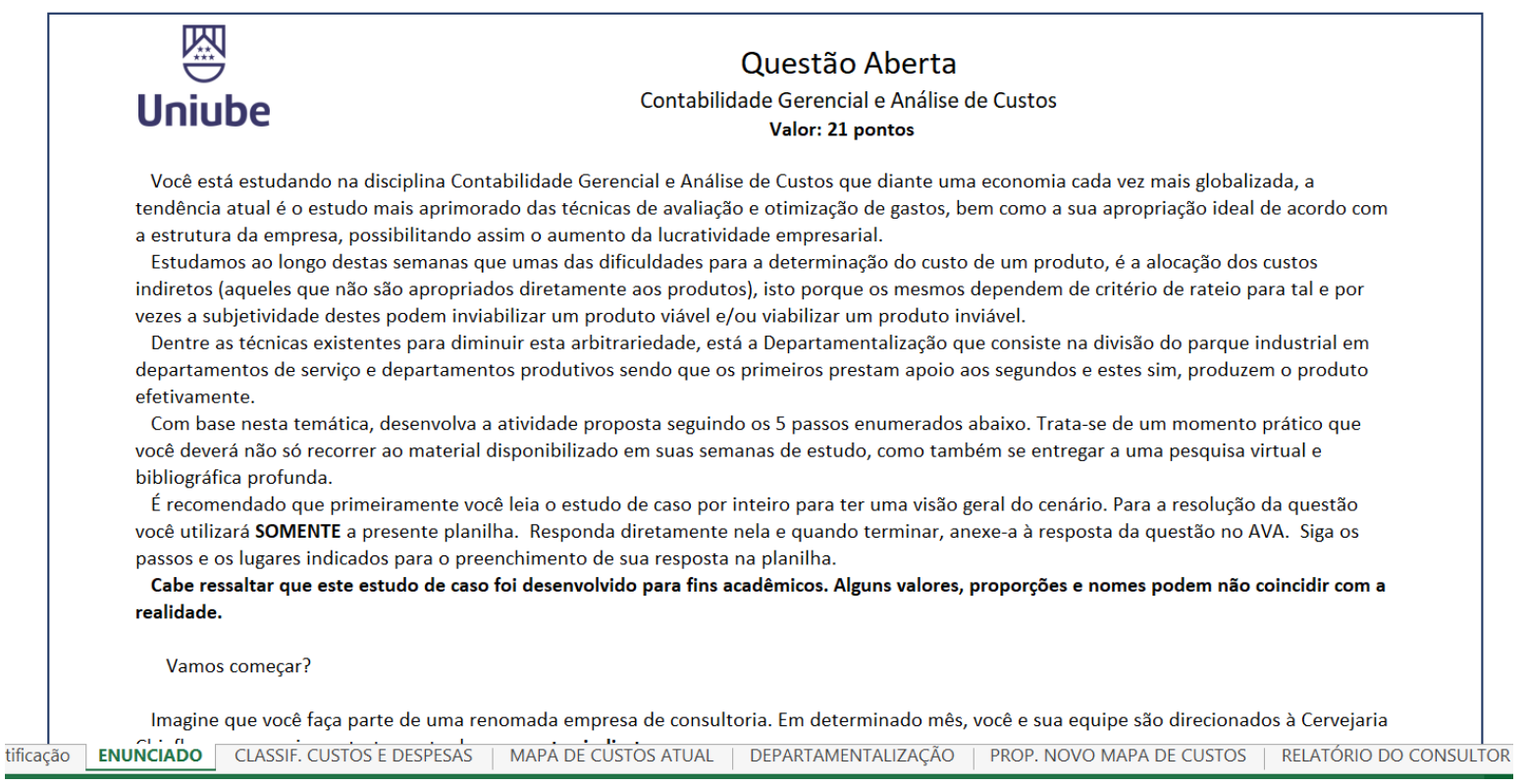

Figura 2 - Enunciado

Depois de efetuar a leitura do enunciado o aluno inicia a resolução da questão construindo o que se pede no passo 1, que estará disponível na aba "Classificação de Custos e Despesas". O objetivo desta fase é que o aluno consiga classificar os gastos elencados em uma lista pertencentes a um cenário fornecido pelo proprietário da 
empresa fictícia. Conforme o aluno vai progredindo na classificação, a planilha vai the apresentando os totalizadores de cada item classificado, quais sejam: custos diretos, custos indiretos e despesas, conforme demonstrado na figura 3. Neste passo o aluno poderá obter até 4 pontos de um total de 21 distribuídos.
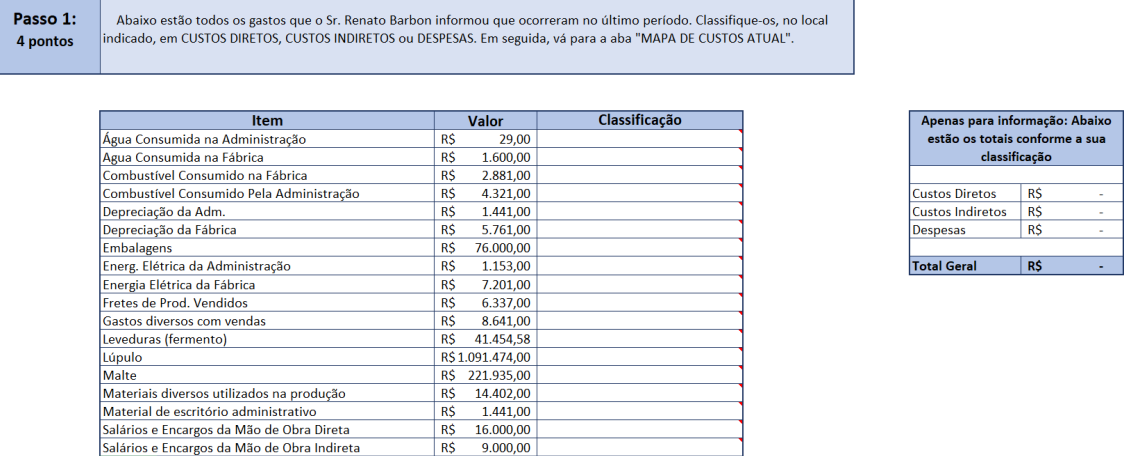

Figura 3 - Classificação de Custos e Despesas.

No segundo passo, o aluno constrói o mapa de custos atual da organização. Para tanto, ele deverá acessar a aba "Mapa de Custos Atual", demonstrada na figura 4, e apropriar os custos diretos e indiretos aos produtos encontrando o custo unitário naquele período em questão. Neste passo o aluno utiliza da classificação feita no passo anterior e poderá obter até 4 pontos de um total de 21 pontos.

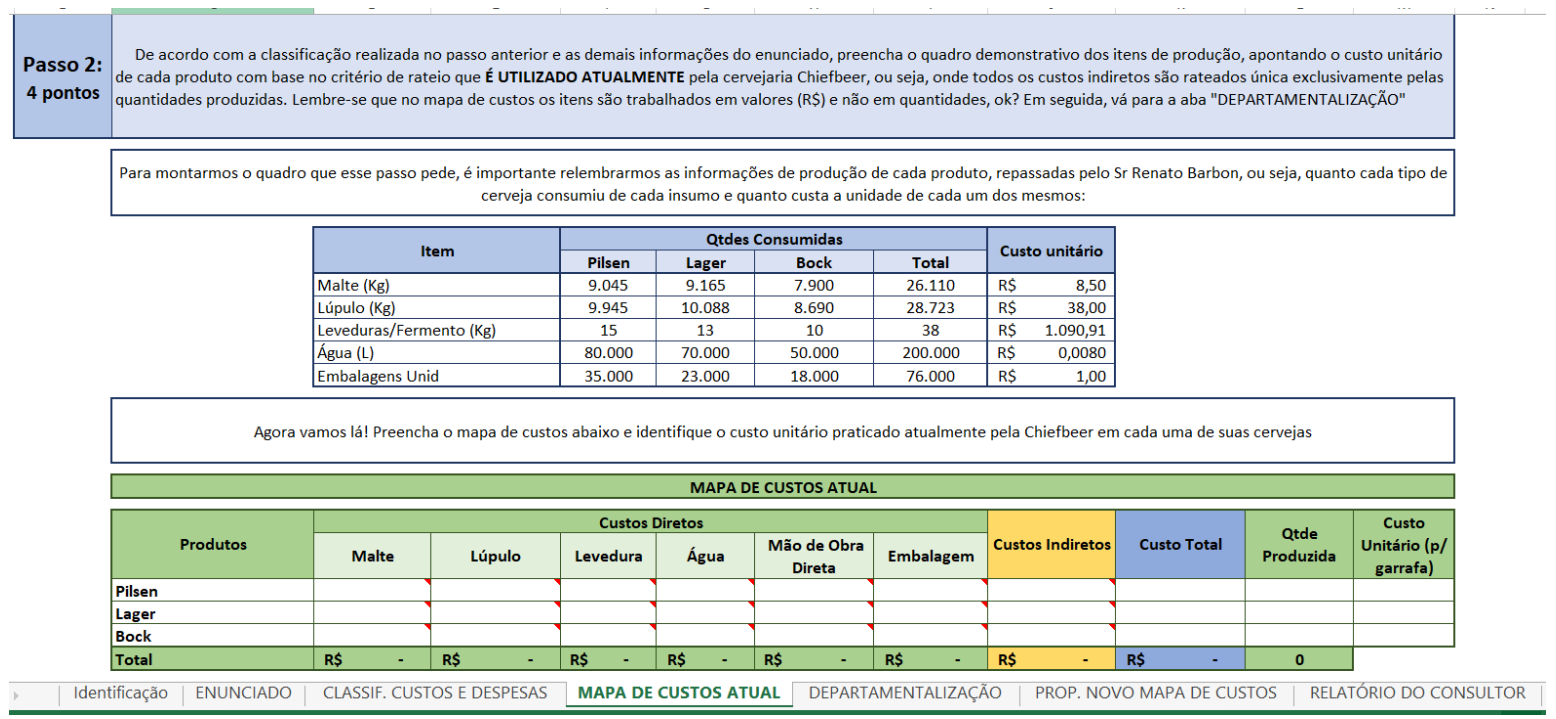

Figura 4 - Mapa de custos atual

No terceiro passo, o aluno acessa a aba "Departamentalização" demonstrada na figura 5 e indicará a distribuição dos custos indiretos utilizando a técnica de mesmo nome. Para tal, o aluno utiliza-se da classificação feita no primeiro passo atrelada às 
informações do enunciado. Nesta fase da atividade o aluno poderá obter até 5 pontos de um total de 21 distribuídos.

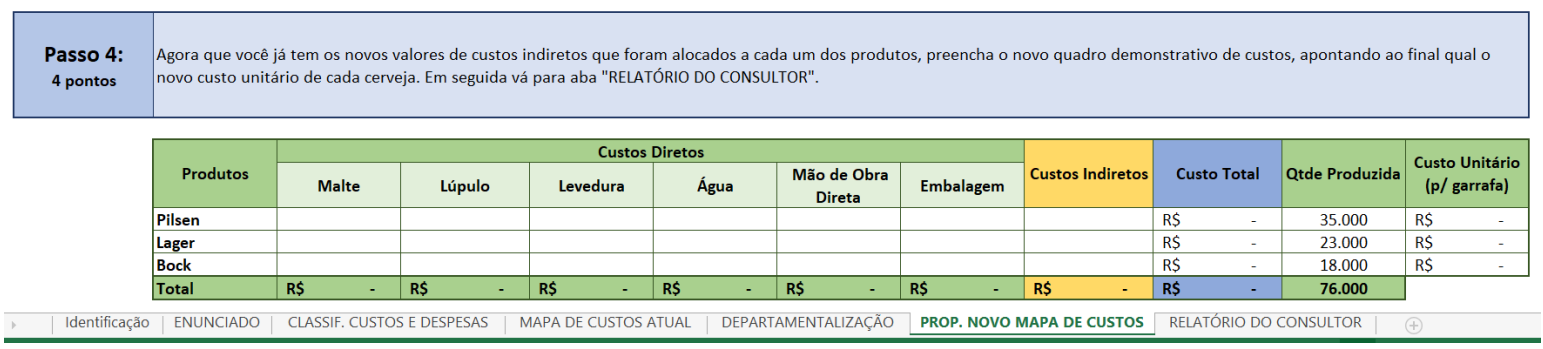

Figura 5 - Departamentalização.

No quarto passo, o aluno apresenta o novo mapa de custos da empresa em análise utilizando agora a departamentalização como critério de apropriação dos custos indiretos. Para tanto, o aluno preenche o mapa presente na aba "Novo Mapa de Custos" demonstrada na figura 6. Neste passo o aluno poderá obter até 4 pontos de um total de 21 pontos distribuídos.

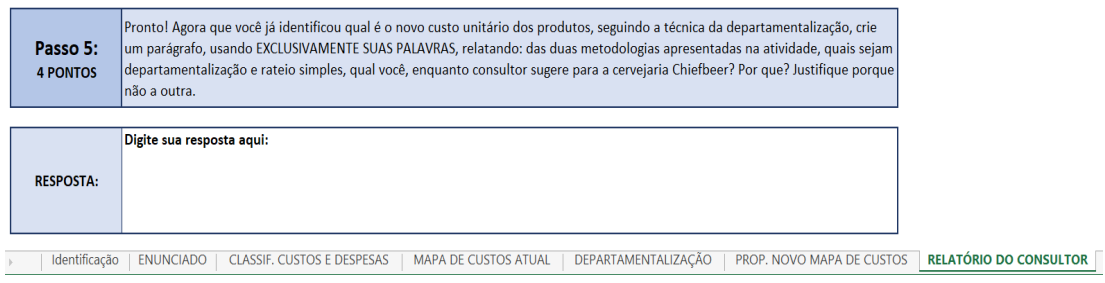

Figura 6 - Novo mapa de custos.

Por fim, no quinto passo, o aluno terá a oportunidade de construir um relatório emitindo seu parecer técnico com relação ao trabalho produzido e o resultado auferido. Deverá apontar, de acordo com o conhecimento adquirido durante as semanas de estudos, qual técnica é a mais indicada para a formação do custo unitário de cada produto da empresa e o motive que justifica a escolha. Para inserir seu relatório o aluno acessa a aba "Relatório do Consultor", demonstrada na figura 7. 
REFERENCIAL

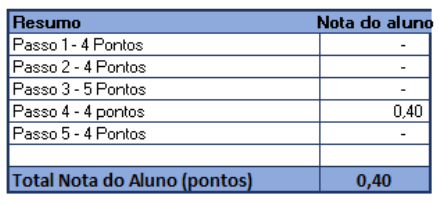

UBSS: Prot. I utor, a planılha nāo corrıge o passo

5 automaticamente. Portanto, favor analisar a

resposta do aluno conforme o referencial e

depois retornar ao resumo para visualizar a nota

PASSO 1 - 4 PONTOS



TOTAL

R5 1.511.071,58

Figura 7 - Relatório do consultor.

Como a atividade é avaliada?

A correção da planilha se dará de forma automatizada, visto que a própria planilha foi construída para tal fim. O professor tutor deverá corrigir apenas o quinto passo, visto que, por se tratar de texto não foi possível ou a correção automática. A aba "Referencial" fica oculta para o aluno e é acessada apenas mediante a digitação de senha conhecida apenas pelo professor responsável e tutores. Nela, foi disponibilizada a correção efetuada para cada campo que o aluno preencheu e apresenta um resumo da nota obtida após a resolução.

\section{Critérios de pontuação}

Quanto aos critérios de pontuação, no primeiro passo a atividade é composta por dezoito itens a serem classificados. Cada acerto corresponde a 0,22 pontos de um total de 4 pontos. No segundo passo no qual o aluno preenche o mapa de custo atual da empresa há 30 campos sendo que cada um que for preenchido corretamente garantirá ao aluno 0,13 pontos de um total de 4 pontos. No terceiro passo ao desenvolver a técnica da departamentalização, ponto chave da questão o aluno poderá receber até 5 pontos sendo que cada resposta correta dentre os 32 campos a serem preenchidos, possui um valor de 0,16 pontos. No quarto passo ao preencher um novo mapa de custos 
considerando os valores encontrados no item anterior há 30 campos totalizando 4 pontos que corresponde a 0,13 pontos para cada acerto. Por fim, no quinto passo 0 aluno produzirá um relatório sobre qual das duas metodologias apresentadas na atividade, quais sejam departamentalização e rateio simples, ele enquanto consultor sugere para a empresa. Deverá ainda justificar seu posicionamento. Este passo tem valor total de 4 pontos e será atribuído $70 \%$ da nota caso o aluno indique a departamentalização e outros $30 \%$ caso ele faça a análise das diferenças no custo unitário dos produtos.

Resultados

Tendo em vista a importância das informações no processo de gestão organizacional, a atividade aqui socializada tem contribuído para o objetivo proposto pela contabilidade proposto por Sá (1971)

a Contabilidade Gerencial, através de um sistema de informações, métodos e conhecimento da organização e da utilização do planejamento, fornecerá informações para atender à necessidade de seus usuários, com relatórios que demonstram os resultados por atividades, comparando-se o planejado com o realizado, para análise da gestão organizacional.

Os alunos têm demonstrado competência para identificar os fundamentos teóricos e práticos necessários para gestão de custos bem como avaliar diversos conceitos e técnicas normalmente usadas no planejamento, controle operacional e em processos de tomadas de decisão. A metodologia adotada considera a natureza, as necessidade e especificidades da modalidade de ensino, do curso e da formação dos alunos. Assim, utiliza de meios, recursos e tecnologias de informação e comunicação no desenvolvimento das diferentes propostas.

A interação entre alunos e professores é garantida pela relação dialógica estabelecida entre os participantes que atuam no processo nos momentos presenciais; por meio da ferramenta de comunicação dentro do ambiente virtual de aprendizagem; nos estudos orientados a distância; nas demais atividades online mediatizadas por professores tutores online ou presenciais; e ainda na forma de guias, manuais e orientações de estudo com tratamento didático pedagógico adequado para a modalidade a distância.

\section{REFERÊNCIAS}

BARBOSA, E. F.; MOURA, D. G. de. Metodologias ativas de aprendizagem na educação profissional e tecnológica. B. Tec. Senac, Rio de Janeiro, v. 39, n.2, p.48-67, maio/ago. 2013.Disponível em: 
http://www.senac.br/media/42471/os_boletim_web_4.pdf. Acesso em: 10 de abril de 2018.

FERREIRA, A. F. et. al. Contabilidade de custos nas universidades norte-americanas: o perfil da disciplina nos cursos de graduação. In: XVIII Congresso Brasileiro de Custos, 2011.Anais eletrônicos... - Rio de Janeiro - RJ, Brasil. Disponível em: file://C:/Users/cliente/Downloads/CBC2011artigo0389.pdf . Acesso em: 13 abril 2018.

KOLIVER, O. Novas metodologias no ensino de custos? In: I Congresso Brasileiro de Gestão de Custos, 1994. Anais eletrônicos... - São Leopoldo, RS, Brasil. Disponível em: http://anaiscbc.emnuvens.com.br/anais/article/view/3518/3518. Acesso em: 10 abr de 2018.

REIS, L. G. dos; TARIFA, M. R.; NOGUEIRA, D. R. O processo de ensino da contabilidade custos e gerencial: uma análise comparativa entre o ensino presencial e 0 ensino a distância. In: XVI Congresso Brasileiro de Custos, 2009. Anais eletrônicos... - Fortaleza, CE, Brasil. Disponível em: http://anaiscbc.emnuvens.com.br/anais/article/viewFile/1116/1116. Acesso em: 11 de abril de 2018.

SÁ, A. L. de. Contabilidade Gerencial. São Paulo: Atlas, 1971.

SILVA, R. H. A.; SCAPIN, L. T. Utilização da avaliação formativa para a implementação da problematização como método ativo de ensino-aprendizagem. Est. Aval. Educ., São Paulo, v. 22, n. 50, p. 537-552, set./dez. 2011. Disponível em: http://www.fcc.org.br/pesquisa/publicacoes/eae/arquivos/1665/1665.pdf. Acesso em: 10 abril de 2018. 